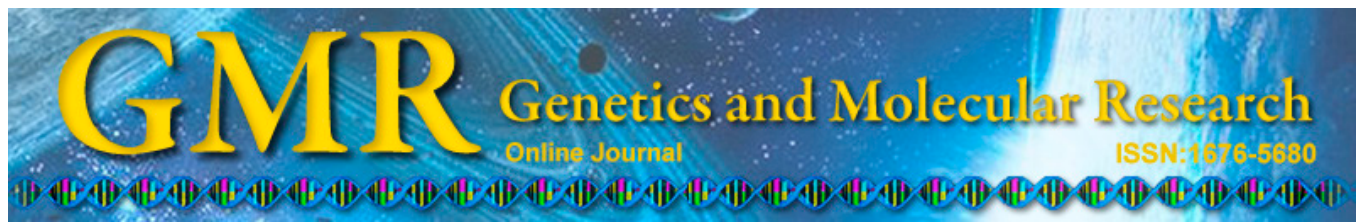

\title{
Differential gene expression in drought-tolerant sugarcane roots
}

\author{
J.S. Vantini' ${ }^{1}$, G.C. Dedemo ${ }^{1}$, D.F. Jovino Gimenez ${ }^{1}$, L.F.S. Fonseca ${ }^{2}$, \\ R.I.D. Tezza ${ }^{3}$, M.A. Mutton ${ }^{4}$, J.A. Ferro ${ }^{1}$ and M.I.T. Ferro ${ }^{1}$ \\ ${ }^{1}$ Laboratório de Bioquímica e Biologia Molecular, Departamento de Tecnologia, \\ Faculdade de Ciências Ágrarias e Veterinárias, Universidade Estadual Paulista, \\ Jaboticabal, SP, Brasil \\ ${ }^{2}$ Departamento de Zootecnia, Faculdade de Ciências Ágrarias e Veterinárias, \\ Universidade Estadual Paulista, Jaboticabal, SP, Brasil \\ ${ }^{3}$ Centro de Recursos Biológicos e Biologia Genômica, \\ Universidade Estadual Paulista, Jaboticabal, SP, Brasil \\ ${ }^{4}$ Departamento de Produção Vegetal, \\ Faculdade de Ciências Agrárias e Veterinárias, \\ Universidade Estadual Paulista, Jaboticabal, SP, Brasil \\ Corresponding author: J.S. Vantini \\ E-mail: juvantini@yahoo.com.br
}

Genet. Mol. Res. 14 (2): 7196-7207 (2015)

Received September 5, 2014

Accepted February 26, 2015

Published June 29, 2015

DOI http://dx.doi.org/10.4238/2015.June.29.13

\begin{abstract}
Drought is one of the most frequent abiotic stresses limiting the productivity and geographical distribution of sugarcane culture. The use of drought-tolerant genotypes is one approach for overcoming the effects of water stress. We conducted a comparative study to identify gene expression profiles under water stress in tolerant sugarcane roots. Two different cultivars, 1 drought tolerant (RB867515) and 1 drought susceptible (SP86-155), were evaluated at 4 sampling time points $(1,3,5$, and 10 days) using the cDNA-amplified fragment length polymorphism technique. A total of 173 fragments were found to be differentially expressed in response to water stress in the tolerant cultivar. Seventy of these were cloned, sequenced, and categorized. Similarity analysis using
\end{abstract}


BLAST revealed that $64 \%$ of the fragments differentially expressed code proteins classified as no hits $(23 \%)$, hypothetical $(21 \%)$, or involved in stress response $(20 \%)$, with others were involved in communication pathways and signal transduction, bioenergetics, secondary metabolism, and growth and development. Four genes were analyzed and validated using real-time quantitative polymerase chain reaction to determine their expression and showed consistency with the cDNA-amplified fragment length polymorphism analyses. Our results contribute insight into the molecular responses to water stress in sugarcane and possibility to the development of cultivars with improved tolerance to drought.

Key words: Abiotic stress tolerance; Saccharum spp; Chaperones; cDNA-amplified fragment length polymorphism;

Quantitative reverse transcription-polymerase chain reaction

\section{INTRODUCTION}

Sugarcane (Saccharum officinarum L.) culture is extremely important in tropical countries (Azevedo et al., 2011). Its expansion in Brazil has been driven by the growing worldwide demand for biofuels (Endres et al., 2010). Numerous environmental factors can have negative effects on the increase and expansion of sugarcane production, and water stress is one of the most limiting abiotic factors affecting sugarcane productivity (Sales et al., 2012; Dedemo et al., 2013).

Some of the changes during periods of water stress depend on the duration and severity of the stress, plant genotype, and stage of development, as well as the nature of the stress (Kramer and Boyer, 1995; Gao et al., 2013). The root system is the first to detect these changes and to signal their effects to other cells, tissues, and organs. The increased expression of chaperone proteins, proteases, peroxidases, transcription factors, induction of abscisic acid, and increased levels of trehalose, help to reestablish cellular homeostasis and membrane protection (Wang et al., 2003).

The identification of new plant genotypes that are more tolerant to water stress is essential for agriculture and economies worldwide. In addition, genes related to the mechanisms of drought tolerance may increase the understanding of the basic mechanisms in the evolutionary adaptation to this type of stress. These genes can be used in studies of plant transformation to develop drought-tolerant varieties and tested to improve field productivity in agricultural production (Nepomuceno et al., 2001; Lenka et al., 2011; Kido et al., 2012). A thorough understanding of the plant response to abiotic stress at the molecular level is a prerequisite for its effective management (Deshmukh et al., 2014).

Several techniques have been used to identify drought-responsive genes (Kido et al., 2012), and the cDNA-amplified fragment length polymorphism (cDNA-AFLP) technique widely used to identify genes that are differentially expressed in tolerant plants in response to biotic or abiotic stresses. This technique is rapid, inexpensive, reproducible, sensitive, and has been successfully used previously for this purpose in sugarcane (Que et al., 2011).

Thus, we conducted a comparative analysis of gene expression profiles between root tissues from a drought-tolerant sugarcane cultivar and a drought-susceptible cultivar. The effects of water stress were evaluated at 4 sampling time points $(1,3,5$, and 10 days) us- 
ing the cDNA-AFLP technique and validated by quantitative real-time reverse transcriptionpolymerase chain reaction (qRT-PCR). Our findings contribute to the understanding of the mechanisms involved in water stress tolerance in plants, and consequently to the development of sugarcane cultivars that are more tolerant to water stress.

\section{MATERIAL AND METHODS}

\section{Plant material and experimental driving}

The experiments were conducted in a greenhouse in Jaboticabal, São Paulo State, Brazil $\left(21^{\circ} 14^{\prime} 39.62^{\prime \prime} \mathrm{S}\right.$ and $48^{\circ} 17^{\prime} 59.00^{\prime \prime} \mathrm{W}$, at an altitude of $\left.609 \mathrm{~m}\right)$ with controlled temperature and humidity $\left(22-31^{\circ} \mathrm{C}\right.$ and relative humidity $\left.=60.44 \pm 17.44 \%\right)$. The drought-tolerant RB867515 and the drought-susceptible SP86-155 sugarcane cultivars were exposed to 2 treatments (drought and watered) at 4 sampling time points (1,3,5, and 10 days); the experiments were performed with 4 replicates.

The cultivars used were originated from a single bud set $(7 \mathrm{~cm})$ treated with $0.25 \%$ Priori Xtra ${ }^{\circledR}$ (Syngenta, Basel, Switzerland) systemic fungicide. Homogeneous settlings were transplanted to 14.5 -L plastic pots, with 1 plant per pot, containing Alfisol soil previously subjected to liming and nutrient correction. Pots were irrigated according to weight every 2 days, and the soil moisture was maintained in the range of $65-75 \%$ of field capacity. At 175 days after planting, water stress was applied at the 4 sampling time points (1, 3, 5, and 10 days). Control plants received proper watering as previously stipulated by the field capacity range.

Sugarcane roots from the different treatments were collected at each sampling time point, washed with tap water, washed with MilliQ ultrapure water, immediately transferred to liquid nitrogen, and stored at $-80^{\circ} \mathrm{C}$. Total RNA was extracted from $0.6 \mathrm{~g}$ root tissue material, from each treatment (mixture of 4 biological replicates), using the "Illustrates RNA Isolation RNA Mini Spin" Kit (GE Healthcare, Little Chalfont, UK). The quality of the total RNA extracted was assessed using the Agilent 2100 Bioanalyzer equipment with Pico Lab Chip Kit (Agilent Technologies, Palo Alto, CA, USA). For this, we used the Agilent RNA 6000 Nano kit. Double-stranded cDNA was synthesized from total RNA samples using the Revertaid ${ }^{\mathrm{TM}} \mathrm{H}$ Minus First Strand cDNA synthesis kit (Fermentas, Vilnius, Lithuania) and purified using the phenol-chloroform method according to Sambrook et al. (1989).

\section{cDNA-AFLP technique}

The cDNA-AFLP technique was performed using the AFLP ${ }^{\circledR}$ Plant Mapping Kit (Regular Plant Genomes) from PE-Applied Biosystems, Inc. (Foster City, CA, USA) using the cDNA samples. Nine primer combinations, deemed efficient in monocots, were used for the described primer sequences of EcoRI (GACTGCCTACCAATTC---) and MseI (GATGA GTCCTGAGTAA---): AAC/CAG, AGG/CAT; ACT/CTA; ACG/CAC; AGC/CAC; AGG/ CTT; AAG/CTT, AAC/CTC, and AAG/CTC. The method used was as described by Vos et al. (1995); subsequent staining with silver nitrate (Creste, 2001) was used in the analysis and differentially expressed fragments (DEF) were counted in the stressed drought-tolerant cultivar.

PCR fragments from differentially expressed genes amplified from the stressed drought-tolerant cultivar were removed from the gel using the method described by Pathan et al. (2007). These samples were re-amplified and re-selected according to their expected 
sizes in a $1 \%$ agarose gel. These fragments were purified (Wizard ${ }^{\mathbb{B}}$ SV Gel and PCR Clean-up system kit (Promega, Madison, WI, USA) and cloned into a vector using the pGEM $^{\circledR}$-T Easy Vector System I (Promega). Positive clones were selected among DH10B transformed cells.

DNA sequencing and subsequent analysis of the DEF stressed drought-tolerant cultivar were performed at the Center for Genomic Biology and Biological Resources from the FCAV/UNESP Jaboticabal, SP. Analysis was performed using the BLAST tool (Altschul et al., 1990), public databases provided by NCBI (National Center for Biotechnology Information, http://www.ncbi. nlm.nih.gov/), and SUCEST (http://sucest-fun.org/). An e-value lower than -08 was considered acceptable. The UniProtKB website (http:www.uniprot.org) was used for categorization.

\section{Real-time quantitative PCR}

FASTA sequences were analyzed using the program Repeat Masker (www.repeatmasker.org/), which masks sequences showing similarity. The primers used for the real-time quantitative PCR reactions were designed using the software Primer Express v3.0 (Applied Biosystems); their sequences are shown in Table 1.

These reactions were performed using Power Master Mix SYBR Green in 96-wells plates, and $\Delta \mathrm{Ct}$ analysis was executed using the program Expression Suite Software v1.01 (Applied Biosystems). The normalization of endogenous genes was carried out using the Expression Suite Software v1.01 (Applied Biosystems) (Vandesompele et al., 2002) and the NormFinder program (Andersen et al., 2004). Data were analyzed using the $2^{-\Delta \Delta \mathrm{Ct}}$ method.

\begin{tabular}{|c|c|}
\hline Protein & Primers' sequences \\
\hline 14-3-3 Protein 1 & $\begin{array}{l}\text { F: 5' gAg CCA gAT CAg CAA gAg CAA T 3' } \\
\text { R: 5' gCg gAg AgC ACC ATg AAT g 3' }\end{array}$ \\
\hline Actin $^{1}$ & $\begin{array}{l}\text { F: 5' ATg gAg gCT gCT ggA ATC C } 3^{\prime} \\
\text { R: } 5^{\prime} \text { ATC CAC gTC gCA CTT CAT gA } 3^{\prime}\end{array}$ \\
\hline$\beta$-tubulin ${ }^{1}$ & $\begin{array}{l}\text { F: 5' ggA ggA gTA CCC TgA CAg AAT gA } 3^{\prime} \\
\text { R: } 5^{\prime} \text { Cag TAT Cgg AAA CCT TTg gTg } 3^{\prime}\end{array}$ \\
\hline Disulfide isomerase protein ${ }^{2}$ & $\begin{array}{l}\text { F: 5' Atg ACT TTg gCC ACA CTT TgC } 3^{\prime} \\
\text { R: 5' ggC CTC TCC ACA gCT gCA T 3' }\end{array}$ \\
\hline Trehalose ${ }^{2}$ & $\begin{array}{l}\text { F: 5' TgC CTg CTC ACC ATC gTT 3' } \\
\text { R: 5' TCA Agg TTC CAC ggg TTT AC 3' }\end{array}$ \\
\hline $\mathrm{HSP}^{2} 0^{2}$ & $\begin{array}{l}\text { F: 5' CAA Aag ggA gAC ATC gAA ggT A 3' } \\
\text { R: } 5^{\prime} \text { ggT gAg CTC AAC gTC TTg ATC } 3^{\prime}\end{array}$ \\
\hline DEF $47^{2}$ & $\begin{array}{l}\text { F: 5' TTg CgC ACC TTg TCC TTg T 3' } \\
\text { R: 5' Agg CCC gCg CTA TTg TC } 3^{\prime}\end{array}$ \\
\hline
\end{tabular}

${ }^{1}$ Reference genes; ${ }^{2}$ Target genes; differentially expressed fragments (DEF).

\section{RESULTS}

The cDNA-AFLP analysis with 9 combinations of EcoRI/MseI selective primers allowed for comparison of gene expression profiles in root tissue from a drought-tolerant sugarcane cultivar (RB867515) with a drought-susceptible sugarcane cultivar (SP86-155), both subjected to water stress. A total of 173 differentially expressed fragments (DEFs) were detected in the stressed drought-tolerant cultivar, with sizes ranging from 80 to 1000 base pairs. Seventy of these DEFs were re-amplified, cloned, sequenced, and analyzed by comparison with the NCBI and SUCEST public databases (Table 2).

All DEFs were analyzed using the UniProtKB website for functional classification, 
which predicts the function of proteins in cellular metabolism. Among the 13 identified functional groups (Figure 1), 3 had the highest representation. This includes the $16(23 \%)$ unknown proteins with no hits in the NCBI databases (DEF 2, 4, 12, 13, 25, 28, 29, 31, 33, 37, $40,42,47,53,54$, and 63), the 15 (21\%) hypothetical proteins (DEF 3, 16, 17, 18, 19, 20, 22, $26,35,36,41,43,49,59$, and 67 ), and the $14(20 \%)$ proteins related to stress (DEF 1, 5, 8, $9,23,27,38,39,46,52,58,64,65$, and 66). The others, related to growth and development functions (DEF 34, 55, 60, 61, and 70), secondary metabolism (DEF 32, 44, 51, and 62), lipid metabolism (DEF 30, 48, and 68), communication and signal transduction (DEF 6, 50, and 57), bioenergetics (DEF 45, 56, and 69), dynamics and regulation (DEF 11, 14, and 15), cellular dynamics (DEF 21 and 24), protein metabolism (DEF 10), and carbohydrate metabolism (DEF 7) showed representative values ranging from 1 to $7 \%$ (Figure 1). Most of these genes were expressed at the first 2 sampling time points ( 1 and 3 days) under water stress. This suggests that the signaling cascade genes are activated sooner in response to water stress in the tolerant cultivar than in the non-tolerant cultivar.

The expression of 4 genes was analyzed using quantitative real-time PCR to validate the DEF results from the cDNA-AFLP analysis. Two genes code for proteins related to stress response (DEF 1; DEF 39, 58, and 64), 1 codes for a protein related to bioenergetics (DEF 45), and 1 showed no hit (DEF 47) (Table 2). Figure 2 shows the expression of these targeted genes in the drought-tolerant and drought-susceptible sugarcane cultivars at the 4 sampling time points.

The chaperone disulfide isomerase protein encoding gene (DEF 1) was rapidly induced in the tolerant cultivar under water stress, showing higher expression than the susceptible cultivar at the first sampling time point. The chaperone $h s p 70$ gene (DEF 39, 58, and 64) showed progressive gene expression with increasing stress levels in the tolerant cultivar, where the highest expression was observed at the last sampling time point compared to the susceptible cultivar. The same was observed for the trehalose synthase gene (DEF 45) during stress treatment. However, the no hit gene showed increased gene expression at the 2nd and 4th sampling time points, reaching a peak at the 4th sampling time point, which was higher than in the susceptible cultivar. The 4 patterns of expression observed in the qRT-PCR results confirmed the profiles observed from cDNA-AFLP analysis.

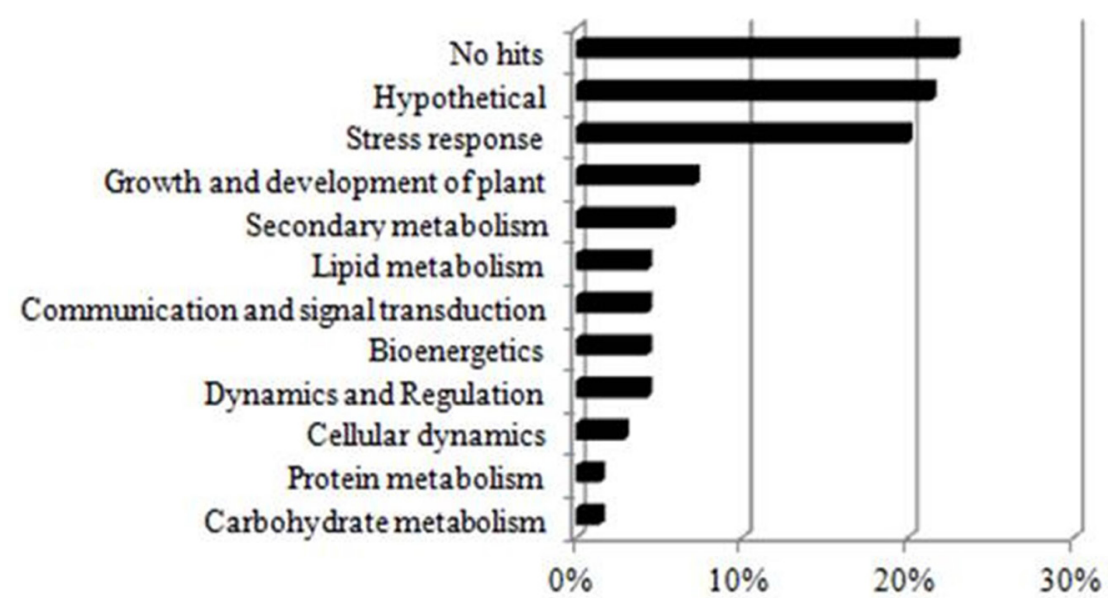

Figure 1. Functional categorization of fragments differentially expressed in the roots of a drought-tolerant sugarcane cultivar, according to UniProtKB (2014). 


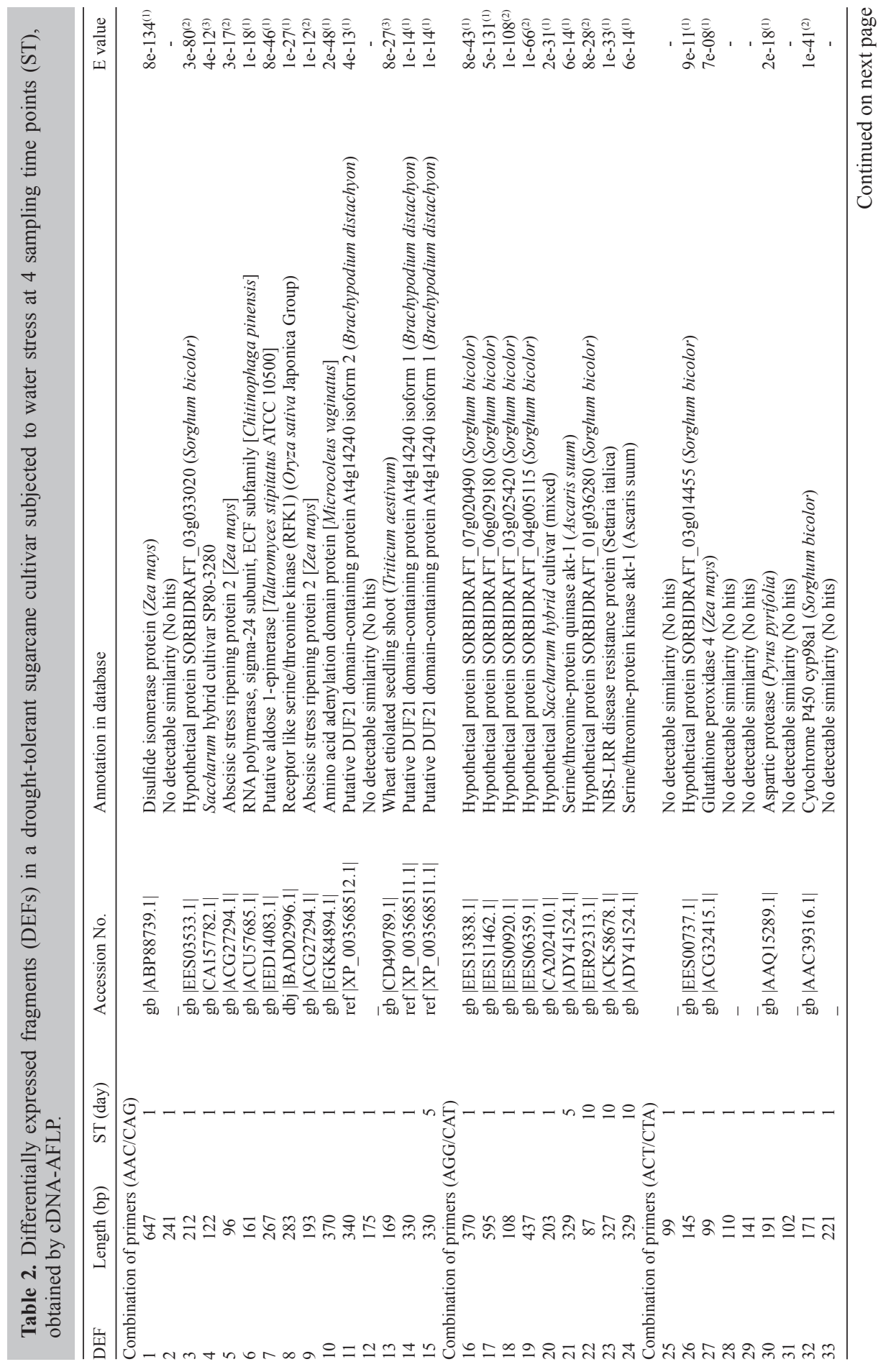




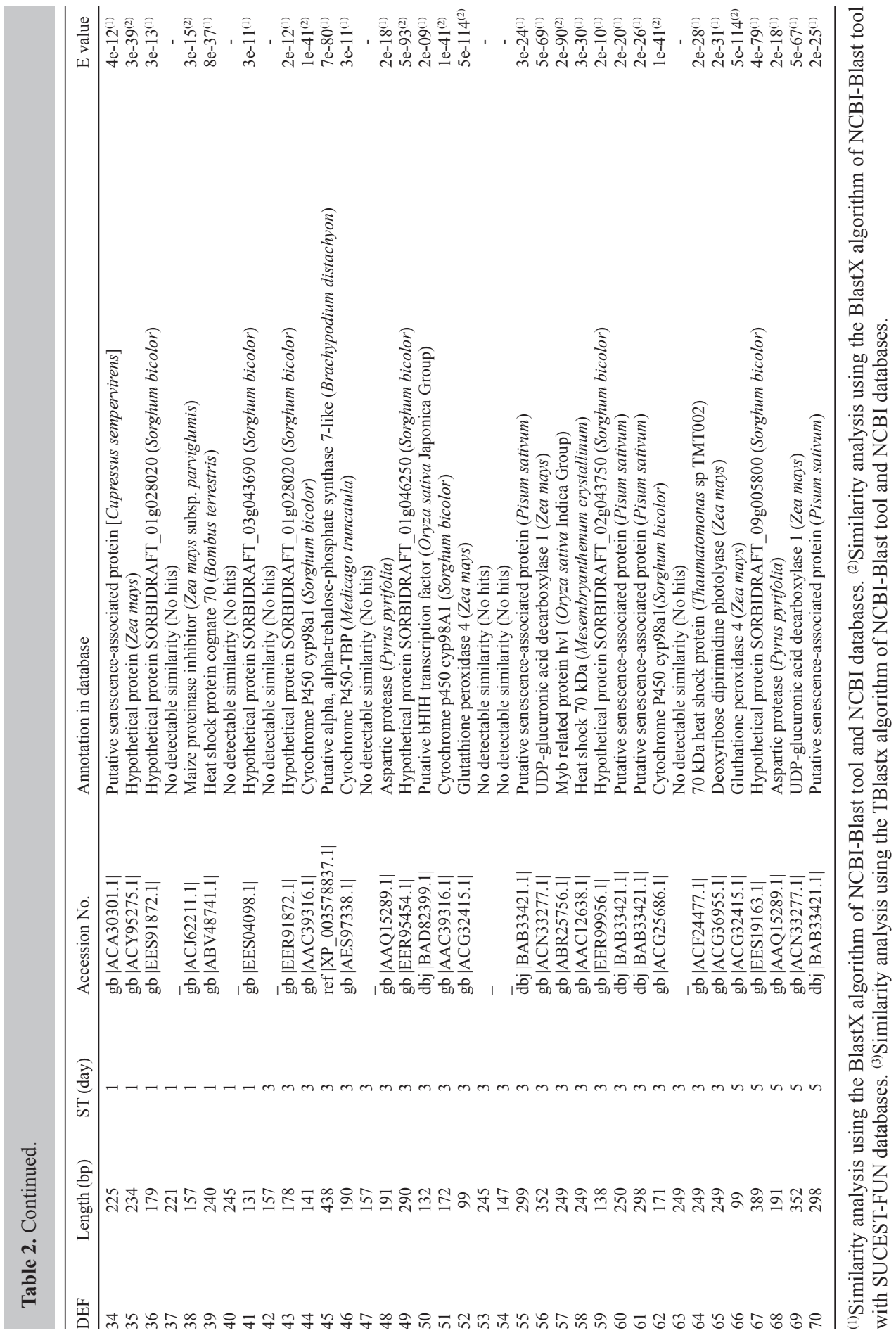



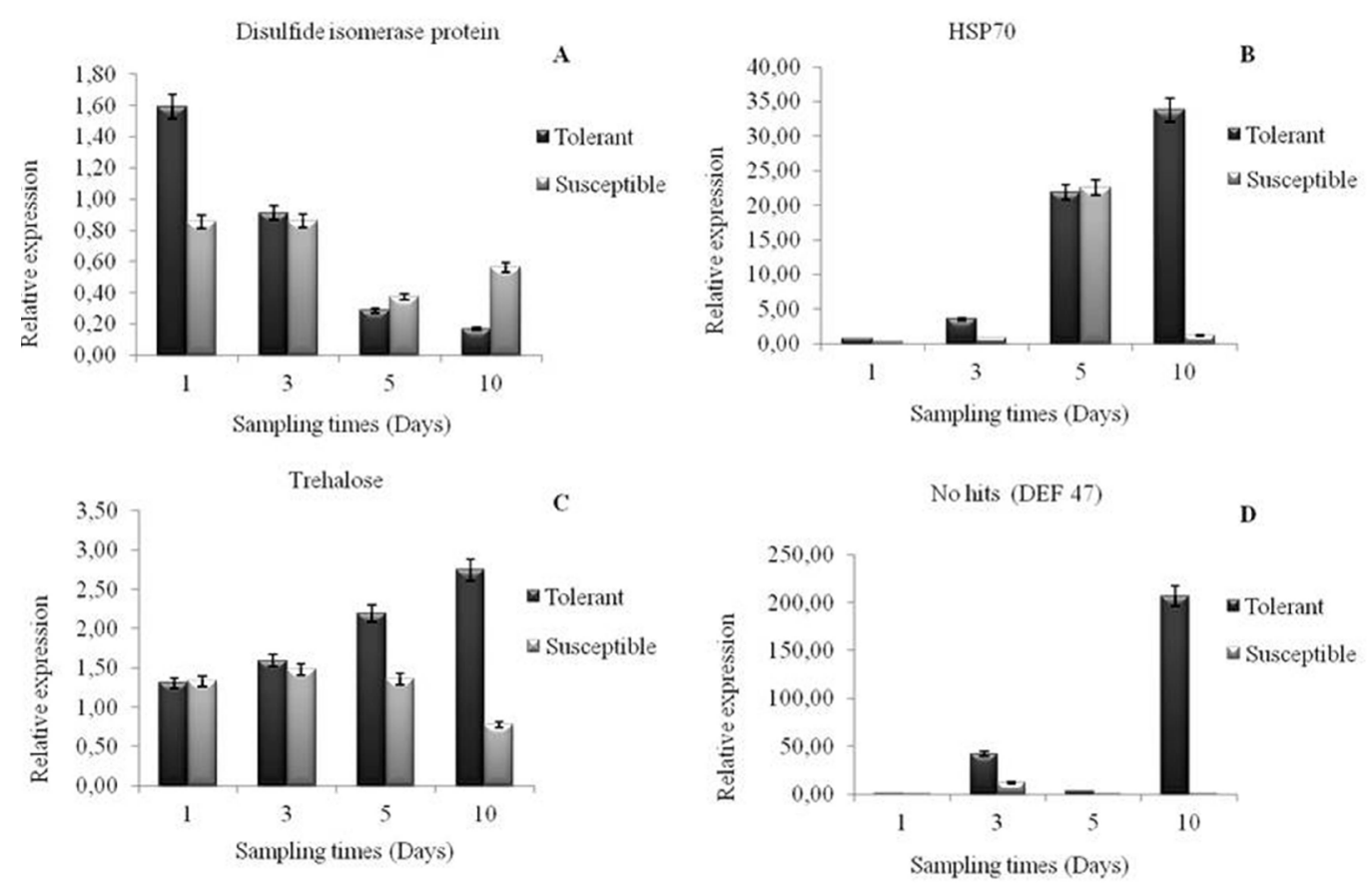

Figure 2. qRT-PCR analysis of the differentially expressed fragments (DEFs) in drought-tolerant and droughtsusceptible sugarcane cultivars in response to water stress at 4 sampling time points $(1,3,5$, and 10 days), respectively. Expression patterns of (A) disulfide isomerase protein (chaperone), (B) HSP70 protein (chaperone), (C) trehalose, and (D) No hits (DEF 47).

\section{DISCUSSION}

Investigating how plants cope with different abiotic stresses - mainly drought and extreme temperatures - is pivotal for both understanding underlying signaling pathways and improving genetically engineered crops (González and Iusem, 2014). The gene encoding the disulfide isomerase protein (DEF 1), a chaperone, expressed in the tolerant cultivar under water stress at the first sampling time point was among the differentially expressed fragments categorized in response to stress. This protein was previously identified in sugarcane under biotic and abiotic stresses (Borges et al., 2001) and in corn under water stress conditions (Wang et al., 2008). Borges et al. (2001) found that during synthesis, some proteins require the assistance of molecular chaperones for correct folding. The rapid induction of this protein at the first sampling time point (confirmed by qRT-PCR) in the RB867515 cultivar may have favored the drought tolerance trait by participating in correctly folding protein synthesized in response to water stress. This rapid gene induction indicates that several proteins were synthesized in response to water stress in the tolerant cultivar.

Another group of genes that encode well-known proteins and show chaperone activities (Sarkar et al., 2013) are heat shock proteins (HSP). In our study, hsp 70 genes were expressed in the tolerant cultivar at the first and second sampling time points (DEF 39, 58, and 64). Approximately $44 \%$ of the Hsp 70 family and its co-chaperone gene expression has been identified in sugarcane under biotic and abiotic stresses (Borges et al., 2001). In potato 
cell cultures under water stress, the induction of 2 HSP family protein expressions was identified by cDNA-AFLP (Ambrosone et al., 2012). We observed a gradual increase in the HSP70 chaperone following water stress according to the qRT-PCR results; the level of this protein peaked at 10 days of stress. This suggests that HSP70 is favored under drought tolerance in the RB867515 cultivar by protecting cells against dehydration when compared to the susceptible cultivar under the same water stress condition. Protein folding is greatly affected by a lack of water; therefore, some chaperones may act to repair damage caused by folding failures.

We also identified the expression of the glutathione peroxidase 4 encoding gene at the first 3 sampling time points (DEF 27, 52, and 66). Boaretto et al. (2014) found that improved performance of tolerant cultivar IACSP 94-2094 under 2 levels of soil water restriction (70 and 30\% Soil Available Water Content) was associated with a more efficient antioxidant system response, particularly under conditions of mild stress, compared the susceptible cultivar IACSP 95-5000. Kido et al. (2012) subjected 20 commercial sugarcane cultivars to water stress for 3,10, and 20 days and observed increased expression in the glutathione peroxidase-encoding gene in tolerant cultivars. According to Dedemo et al. (2013), plants activate enzymes that promote the removal of reactive oxygen species to protect themselves from abiotic stress. Glutathione peroxidase 4 is a universal antioxidant enzyme that protects the cell membrane's lipids (Brigelius-Flohé, 1999). In our study, activation of glutathione peroxidase 4 in the tolerant cultivar may have acted to eliminate reactive oxygen species and protect lipid membranes in sugarcane root cells; these cells were possibly undergoing degradation caused by water stress.

A gene encoding a protease inhibitor protein was also expressed in the tolerant cultivar under water stress at the first sampling time point (DEF 38). According to Medeiros et al. (2012), increased gene expression of the protease inhibitor protein in sugarcane observed in response to attacks by Diatraea saccharalis, was associated with injury caused by this caterpillar. Another study reported that accumulation of this protein in corn was related to mechanical damage (Tamayo et al., 2000). We found that expression of the protease inhibitor protein-encoding gene in the drought-tolerant sugarcane cultivar may be related to root system damage. The root hairs or trichomes break when dried, which can induce protein protease inhibitors.

A gene encoding a protein correlated with abscisic acid (ABA) also showed induced expression under water stress in the tolerant cultivar at the first sampling time point (DEF 5 and 9). Hydraulic signaling led to stomatal closure in sugarcane plants under water stress as well as low water potential. Sales et al. (2012) reported that decreased water content in the leaves indirectly increased ABA concentration in the aerial parts near the guard cells and reduced stomatal opening. Corn plants subjected to drought also showed increased ABA concentration (Bahrun et al., 2002). Our results suggest that at the beginning of water stress, the increase in abscisic acid expression in the tolerant cultivar led to stomatal closure and activation of other stress response mechanisms that favor drought tolerance.

The gene encoding an aspartic protease was also expressed in response to drought at the first 3 sampling time points (DEF 30, 48, and 68). Aspartic proteases (APs) are a large family of proteolytic enzymes found in nearly all organisms. In plants, they are involved in many biological processes, including senescence, stress responses, programmed cell death, and reproduction (Chen et al., 2009; Guo et al., 2013). According to Contour-Ansel et al. (2010), water stress in bean led to the gene expression regulation of an AP gene ( $P v A P 1)$ both at the transcriptional and post-transcriptional levels, which is paramount in the conservation 
of cellular homeostasis and recovery. In other experiment examining drought in Arabidopsis, Yao et al. (2012) identified an AP gene (ASPG1) that may function in drought avoidance through ABA signaling in guard cells. These authors also found that overexpression of the ASPG1 gene enhanced ABA sensitivity in guard cells and reduced water loss in ectopically overexpressing ASPG1 transgenic plants. In our study, the differential expression of the aspartic protease gene in the tolerant cultivar may have led to increased production of ABA in guard cells, favoring stomatal closure and reducing water loss through the leaves.

We also detected differential expression of the gene coding a trehalose-phosphate synthase at the second sampling time point (DEF 45), an enzyme involved in the synthesis of trehalose in plants. Numerous studies have correlated trehalose with tolerance to abiotic stresses in plants, particularly drought (Paul et al., 2008). El-Bashiti et al. (2005) showed that trehalose may play a role as an osmoprotectant compound in wheat species under salt and drought stress conditions. Zhang et al. (2006) demonstrated that transgenic sugarcane transformed with the Grifola frondosa trehalose synthase (TSase) gene accumulated high levels of trehalose and showed enhanced tolerance to drought. In another experiment, Li et al. (2011) showed that in rice, the overexpression of trehalose-6-phosphate synthase enhanced the abiotic stress tolerance of plants by increasing the amount of trehalose and proline, as well as regulating the expression of some stress-related genes. The tolerant cultivar showed differential trehalose gene expression levels.

In this study, a serine/threonine kinase receptor belonging to the leucine-rich repeatribonuclease inhibitor superfamily was identified at the first sampling time point (DEF 8). In sugarcane under water stress, kinase receptors are involved in the signal transduction response to stress (Gupta et al., 2010). In Arabidopsis under some abiotic, biotic, and hormonal stress treatments, these receptors are involved in various signaling processes (Chae et al., 2009). In our study, this receptor may have acted together with a signaling cascade and gene activation in response to the drought tolerance trait.

In addition, expression of 2 transcription factors, bHLH (DEF 50) and Myb (DEF 57), were induced at the 2 nd sampling time point. Abe et al. (2003) showed that transgenic plants overexpressing AtMYC2 (bHLH) and/or AtMYB2 (MYB) cDNAs were more sensitive to ABA. These results indicate that both proteins function as transcriptional activators in ABA-inducible gene expression under drought stress in plants. Du et al. (2013) found that the cooperative interaction between MYB and bHLH was a classic example of combinatorial regulation and that the MYB-related genes likely contributed to drought response. These transcription factors are very important, as they are involved in numerous biotic and abiotic stress plant responses, such as the production of anthocyanins. Anthocyanins are involved in specific developmental stages and can be induced by several environmental factors, including visible and UVB radiation, cold temperatures, and water stress (Scott, 1999; Gonzalez et al., 2008). In this study, these transcription factors may have activated a cascade of genes related to plant defense in response to water stress.

The DEFs categorized as hypothetical and those showing no detectable similarity (no hits) had high representation values of 21 and $23 \%$, respectively. The hypothetical proteins are candidates for further studies to determine their functions; those that showed no detectable similarity are likely unknown genes potentially involved in cellular mechanisms that control the responses to drought in sugarcane. Genes from other functional groups also function in the biochemical machinery in tolerant sugarcane plants in response to water stress.

The DEFs detected in the studied drought-tolerant sugarcane cultivar (RB867515) 
play an important role in signaling responses to water stress and stress management in plants. Thus, this study contributes new insight into the molecular responses to drought in sugarcane and to the development of cultivars with improved tolerance of water stress.

\section{Conflicts of interest}

The authors declare no conflict of interest.

\section{ACKNOWLEDGMENTS}

Research supported by the Coordenação de Aperfeiçoamento de Pessoal de Nível Superior (CAPES). The authors thank Dr. Luciana Rossini Pinto and Dr. Silvana Aparecida de Souza Dias Creste and MSc. Bruna Sousa Gonçalves from the Instituto Agronômico de Cana-deAçúcar (IAC/Ribeirão Preto, SP, Brazil) for all intensive collaboration, help, and guidance. We would like also to thank CREBIO (Centro de Recursos Biológicos e Biologia Genômica, UNESP-FCAV, Jaboticabal-SP, Brazil) for DNA sequencing and subsequent analysis of the results.

\section{REFERENCES}

Abe H, Urao T, Ito T, Seki M, et al. (2003). Arabidopsis AtMYC2 (bHLH) and AtMYB2 (MYB) function as transcriptional activators in abscisic acid signaling. Plant Cell 15: 63-78.

Altschul SF, Gish W, Miller W, Myers EW, et al. (1990). Basic local alignment search tool. J. Mol. Biol. 215: 403-410.

Ambrosone A, Di Giacomo M, Leone A, Grillo MS, et al. (2012) Identification of early induced genes upon water deficit in potato cell cultures by cDNA-AFLP. J. Plant Res. 126: 169-178.

Andersen CL, Jensen JL and Ørntoft TF (2004). Normalization of real-time quantitative reverse transcription-PCR data: a model-based variance estimation approach to identify genes suited for normalization, applied to bladder and colon cancer data sets. Cancer Res. 64: 5245-5250.

Azevedo RA, Carvalho RF, Cia MC and Gratão PL (2011). Sugarcane under pressure: an overview of biochemical and physiological studies of abiotic stress. Tropical Plant Biol. 4: 42-51.

Bahrun A, Jensen CR, Asch F and Mogensen VO (2002). Drought-induced changes in xylem pH, ionic composition and ABA concentration act as early signals in field grown maize (Zea mays L.). J. Exp. Biol. 53: 251-263.

Boaretto LF, Carvalho G, Borgo L, Creste S, et al. (2014). Water stress reveals differential antioxidant responses of tolerant and non-tolerant sugarcane genotypes. Plant Physiol. Biochem. 74: 165-175.

Borges JC, Peroto MC and Ramos CHI (2001). Molecular chaperone genes in the sugarcane expressed sequence database (SUCEST). Genet. Mol. Biol. 24: 85-92.

Brigelius-Flohé R (1999). Tissue-specific functions of individual glutathione peroxidases. Free Radic. Biol. Med. 27: 951-965.

Chae L, Sudat S, Dudoit S, Zhu T, et al. (2009). Diverse transcriptional programs associated with environmental stress and hormones in the Arabidopsis receptor-like kinase gene family. Mol. Plant 2: 84-107.

Chen J, Ouyang Y, Wang L, Xie W, et al. (2009). Aspartic proteases gene family in rice: gene structure and expression, predicted protein features and phylogenetic relation. Gene 442: 108-108.

Contour-Ansel D, Torres-Franklin ML, Zuily-Fodil Y and de Carvalho MH (2010). An aspartic acid protease from common bean is expressed 'on call' during water stress and early recovery. J. Plant Physiol. 167: 1606-1612.

Creste S, Tulmann-Neto A and Figueira A (2001). Detection of single sequence repeat polymorphisms in denaturing polyacrylamide sequencing gels by silver staining. Plant Mol. Biol. Rep. 19: 299-306.

Dedemo GC, Rodrigues FA, Roberto PG, Bueno Neto C, et al. (2013). Osmoprotection in sugarcane under water deficit conditions. Plant Stress 7: 1-7.

Deshmukh R, Sonah H, Patil G, Chen W, et al. (2014). Integrating omic approaches for abiotic stress tolerance in soybean. Frontiers Plant Sci. 5: 244.

Du H, Wang Y-B, Xie Y, Liang Z, et al. (2013). Genome-wide identification and evolutionary and expression analyses of MYB-related genes in land plants. DNA Res. 20: 437-448.

El-Bashiti T, Hamamci H, Öktem HA and Yücel M (2005). Biochemical analysis of trehalose and its metabolizing enzymes in wheat under abiotic stress conditions. Plant Sci. 169: 47-54. 
Endres L, Silva JV, Ferreira VM and Barbosa GVS (2010). Photosynthesis and water relations in Brazilian sugarcane. TOASJ 4: 31-37.

Gao R, Duan K, Guo G, Du Z, et al. (2013). Comparative transcriptional profiling of two contrasting barley genotypes under salinity stress during the seedling stage. Int. J. Genomics 2013: 1-19.

González RM and Iusem ND (2014). Twenty years of research on Asr (ABA-stress-ripening) genes and proteins. Planta 239: 941-949.

Gonzalez A, Zhao M, Leavitt JM and Lloyd AM (2008). Regulation of the anthocyanin biosynthetic pathway by the TTG1/bHLH/Myb transcriptional complex in Arabidopsis seedlings. Plant J. 53: 814-827.

Guo R, Xu X, Carole B, Li X, et al. (2013). Genome-wide identification, evolutionary and expression analysis of the aspartic protease gene superfamily in grape. BMC Genomics 14: 554-571.

Gupta V, Raghuvanshi S, Gupta A, Saini N, et al. (2010). The water-deficit stress- and red-rot-related genes in sugarcane. Funct. Integr. Genomics 10: 207-214.

Kido ÉA, Ferreira Neto JRC, Silva RLO, Pandolfi V, et al. (2012). New insights in the sugarcane transcriptome responding to drought stress as revealed by superSAGE. Sci. World J. 2012: 1-28.

Kramer PJ and Boyer JS (1995). Water Relations of Plants and Soil. Academic Press, San Diego, CA.

Lenka SK, Katiyar A, Chinnusamy V and Bansal KC (2011). Comparative analysis of drought-responsive transcriptome in Indica rice genotypes with contrasting drought tolerance. Plant Biotechnol. J. 9: 315-327.

Li HW, Zang BS, Deng XW and Wang XP (2011). Overexpression of the trehalose-6-phosphate synthase gene OsTPS1 enhances abiotic stress tolerance in rice. Planta 234: 1007-1018.

Medeiros AH, Franco FP, Matos JL, de Castro PA, et al. (2012). Sugarwin: a sugarcane insect-induced gene with antipathogenic activity. Mol. Plant Microbe Interact. 25: 613-624.

Nepomuceno AL, Neumaier N, Farias JRB and Oya T (2001). Drought tolerance in plants: molecular and physiological mechanisms-Brazil. Biotecnol. Ciênc. e Desenvol. 23: 12-18.

Pathan AA, Uma Devi K, Vogel H and Reineke A (2007). Analysis of differential gene expression in the generalist entomopathogenic fungus Beauveria bassiana (Bals.) Vuillemin grown on different insect cuticular extracts and synthetic medium through cDNA-AFLPs. Fungal Genet. Biol. 44: 1231-1241.

Paul MJ, Primavesi LF, Jhurreea D and Zhang Y (2008). Trehalose metabolism and signaling. Annu. Rev. Plant Biol. 59: 417-441.

Sales CRG, Ribeiro RV, Machado DFSP, Machad RS, et al. (2012). Gas exchange and carbohydrate balance in sugarcane plants under root stressful conditions. Bragantia 71: 319-327.

Sambrook J, Fritsch EF and Maniatis T (1989). Molecular cloning: a laboratory manual. Academic Press, Cold Spring Harbor, NY.

Sarkar NK, Kundnani P and Grover A (2013). Functional analysis of Hsp70 superfamily proteins of rice (Oryza sativa). Cell Stress Chaperones 18: 427-437.

Scott LC (1999). Environmental significance of anthocyanins in plant stress responses. J. Photochem. Photobiol. 70: 1-9.

Tamayo MC, Rufat M, Bravo JM and San Segundo B (2000). Accumulation of a maize proteinase inhibitor in response to wounding and insect feeding, and characterization of its activity toward digestive proteinases of Spodoptera littoralis larvae. Planta 211: 62-71.

Vandesompele J, De Preter K, Pattyn F, Poppe B, et al. (2002). Accurate normalization of real-time quantitative RT-PCR data by geometric averaging of multiple internal control genes. Genome Biol. 3: 1-12.

Vos Pieter, Hogers R, Bleeker M, Reijans M, et al. (1995). AFLP: a new technique for DNA fingerprinting. Nucleic Acids Res. 23: 4407-4414.

Wang W, Vinocur B and Altman A (2003). Plant response to drought, salinity and extreme temperatures: towards genetic engineering for stress tolerance. Planta 218: 1-14.

Wang XT, Huang YQ, Li HY, Shi YS, et al. (2008). cDNA cloning and bioinformatic analysis of protein disulfide isomerase gene of maize Zea mays L. J. Agricul. Univ. Hebei 31: 16-19.

Yao X, Xiong W, Ye T and Wu Y (2012). Overexpression of the aspartic protease ASPG1 gene confers drought avoidance in Arabidopsis. J. Exp. Bot. 63: 2579-2593.

Que YX, Lin JW, Song XX, Xu LP, et al. (2011). Differential gene expression in sugarcane in response to challenge by fungal pathogen Ustilago scitaminea revealed by cDNA-AFLP. J. Biomed. Biotechnol. 2011: 1-10.

Zhang SZ, Yang BP, Feng CL, Chen RK, et al. (2006). Expression of the Grifola frondosa trehalose synthase gene and improvement of drought-tolerance in sugarcane (Saccharum officinarum L). J. Integr. Plant Biol. 48: 453-459. 